\title{
Contribution of Adenylyl Cyclase Modulation of Pre- and Postsynaptic GABA Neurotransmission to Morphine Antinociception and Tolerance
}

\author{
Erin N Bobeck', QiLiang Chen², Michael M Morgan' and Susan L Ingram*,2 \\ 'Department of Psychology, Washington State University, Vancouver, WA, USA; ²Department of Neurological Surgery, Oregon Health \& Science \\ University, Portland, OR, USA
}

\begin{abstract}
Opioid inhibition of presynaptic GABA release in the ventrolateral periaqueductal gray (vIPAG) activates the descending antinociception pathway. Tolerance to repeated opioid administration is associated with upregulation of adenylyl cyclase activity. The objective of these studies was to test the hypothesis that adenylyl cyclase contributes to opioid tolerance by modulating GABA neurotransmission. Repeated microinjections of morphine or the adenylyl cyclase activator NKH477 into the VIPAG decreased morphine antinociception as would be expected with the development of tolerance. Conversely, microinjection of the adenylyl cyclase inhibitor SQ22536 reversed both the development and expression of morphine tolerance. These behavioral results indicate that morphine tolerance is dependent on adenylyl cyclase activation. Electrophysiological experiments revealed that acute activation of adenylyl cyclase with forskolin increased the frequency of presynaptic GABA release. However, recordings from rats treated with repeated morphine administration did not exhibit increased basal miniature inhibitory postsynaptic current (mIPSC) frequency but showed a decrease in mean amplitude of mIPSCs indicating that repeated morphine administration modulates postsynaptic GABA $A$ receptors without affecting the probability of presynaptic GABA release. SQ22536 reversed this change in mIPSC amplitude and inhibited mIPSC frequency selectively in morphine tolerant rats. Repeated morphine or NKH477 administration also decreased antinociception induced by microinjection of the GABA $A$ receptor antagonist bicuculline, further demonstrating changes in GABA neurotransmission with morphine tolerance. These results show that the upregulation of adenylyl cyclase caused by repeated vIPAG morphine administration produces antinociceptive tolerance by modulating both pre- and postsynaptic GABA neurotransmission.

Neuropsychopharmacology (20I4) 39, 2I42-2 I52; doi:I0.1038/npp.20I4.62; published online 9 April 2014
\end{abstract}

\section{INTRODUCTION}

Opioids are the most commonly used drugs to treat severe and chronic pain. The effectiveness of opioids, especially morphine, is reduced over time because of the development of antinociceptive tolerance. Many cellular changes are produced by chronic morphine administration (Williams et al, 2013), but the cellular mechanisms underlying morphine tolerance are not understood. Chronic opioid administration results in upregulated adenylyl cyclase activity and increased cyclic adenosine monophosphate levels (Sharma et al, 1975; Avidor-Reiss et al, 1996; Shy et al, 2008) that have been hypothesized as cellular mechanisms for morphine withdrawal and tolerance (Wang and Gintzler, 1995; Gintzler and Chakrabarti, 2008; Shy et al, 2008). Indeed, inhibition of the adenylyl cyclase-protein kinase A (PKA) pathway during morphine

* Correspondence: Dr SL Ingram, Department of Neurological Surgery, Oregon Health \& Science University, 3।8I Southwest Sam Jackson Park Road, Portland, OR 97239, USA, Tel: +503 494 1220, Fax: +504 494 2664, E-mail: ingrams@ohsu.edu

Received 6 September 2013; revised 4 March 2014; accepted II

March 2014; accepted article preview online 13 March 2014 pretreatment blocks the development of morphine tolerance (Ma and Pan, 2006; Gabra et al, 2008) and dependence (Punch et al, 1997; Li et al, 2006; Madhavan et al, 2010). However, it is not known how modulation of adenylyl cyclase activity leads to changes in antinociception.

The present study focused on the ventrolateral periaqueductal gray (vlPAG) because it is part of a descending pain modulatory system that is important in the development of tolerance to systemic morphine administration (Lane et al, 2005). The vlPAG projects to the rostral ventromedial medulla (RVM) and then to the dorsal horn of the spinal cord (Heinricher and Ingram, 2008; Morgan et al, 2008). Morphine administered into the vlPAG produces antinociception (Jacquet and Lajtha, 1974; Morgan et al, 2005; Morgan et al, 2006) and repeated administration of morphine induces antinociceptive tolerance (Tortorici et al, 1999; Morgan et al, 2006). Morphine antinociception within the vlPAG is mediated by inhibition of presynaptic GABA release, disinhibiting PAG-RVM output neurons (Morgan et al, 2003; Fields et al, 2005). Thus, it is not surprising that opioid-independent antinociception can be elicited by blocking postsynaptic $\mathrm{GABA}_{\mathrm{A}}$ receptors with microinjecting the $\mathrm{GABA}_{\mathrm{A}}$ receptor antagonist bicuculline into the vlPAG (Morgan et al, 2003). 
Opioids inhibit GABAergic synaptic transmission in the vlPAG by activating the phospholipase A2 signaling pathway in presynaptic terminals (Vaughan et al, 1997). However, this mu-opioid receptor (MOP) signaling in presynaptic terminals becomes dependent on adenylyl cyclase after continuous administration of morphine (Ingram et al, 1998). Upregulation of adenylyl cyclase and PKA activity has been demonstrated to occur in many brain areas following chronic opioid administration (Jolas et al, 2000; $\mathrm{Ma}$ and Pan, 2006) and mediates naloxone-precipitated withdrawal behaviors (Bagley et al, 2011). In the ventral tegmental area, upregulation of adenylyl cyclase increases presynaptic GABA release and blockade of the signaling reduces naloxone-precipitated withdrawal (Madhavan et al, 2010). However, our morphine administration paradigm (repeated $5 \mathrm{mg} / \mathrm{kg}$ injections for 3 days) induces antinociceptive tolerance without obvious withdrawal behaviors (Ingram et al, 2008), so it is not known if similar compensatory changes in GABA neurotransmission via adenylyl cyclase in the vlPAG contribute to morphine tolerance. We hypothesized that repeated morphine administration induces antinociceptive tolerance in the vlPAG by altering the probability of presynaptic GABA release. Behavioral experiments were conducted using vlPAG microinjections of adenylyl cyclase activators and inhibitors to determine the role of adenylyl cyclase in antinociceptive tolerance. Electrophysiological experiments investigated changes in presynaptic and postsynaptic GABA neurotransmission in morphine-tolerant animals.

\section{MATERIALS AND METHODS}

\section{Behavioral Experiments}

Animals. Male Sprague-Dawley rats (Harlan Laboratories, Livermore, CA) weighing 200-340 g were used. Rats were housed individually on a reverse $12 \mathrm{~h}$ light cycle (off at 0700 hours) to perform testing during their active dark phase. Food and water were available at all times except during surgical and testing procedures. All procedures were conducted in accordance with the guidelines for animal use described by the International Association for the Study of Pain and approved by the Washington State University and Oregon Health \& Science University Animal Care and Use Committees.

Microinjections. Rats were anesthetized with pentobarbital $(60 \mathrm{mg} / \mathrm{kg}$; i.p.) and a $9-\mathrm{mm}$ guide cannula $(23 \mathrm{G})$ was implanted into the vlPAG using stereotaxic techniques (AP: $+1.7 \mathrm{~mm}$, ML: $\pm 0.6 \mathrm{~mm}$, DV: $-4.6 \mathrm{~mm}$ from lambda). Dental cement anchored the guide cannula to two screws in the skull. A stylet was inserted into the guide cannula following surgery, and rats were allowed to recover under a heat lamp until awake. Morphine sulfate (a gift from the National Institute on Drug Abuse), NKH477 (Tocris Bioscience, Minneapolis, MN), SQ22536 (Tocris Bioscience), bicuculline methioide (Sigma-Aldrich, St Louis, MO) were administered through a 31-G injection cannula into and extending $2 \mathrm{~mm}$ beyond the guide cannula. One day before testing, the injector was inserted into the guide cannula without drug administration to habituate the rat to the procedure. Microinjections were administered in a volume of $0.4 \mu \mathrm{l}$ at a rate of $0.1 \mu \mathrm{l} / 10 \mathrm{~s}$. To minimize backflow up the cannula tract, the injector remained in place an additional 20 s. A stylet was inserted into the guide cannula and the rat was returned to its home cage immediately following the injection.

Behavioral testing. Nociception was assessed using the hot plate test, which measures the latency for the rat to lick the hind paw when placed on a $52.5^{\circ} \mathrm{C}$ hot plate. The rat was removed if no response occurred within $50 \mathrm{~s}$. Tolerance was induced by twice daily microinjections of morphine $(5 \mu \mathrm{g} /$ $0.4 \mu \mathrm{l})$ or saline $(0.4 \mu \mathrm{l})$ into the vlPAG for 3 days. The role of adenylyl cyclase was investigated by microinjecting an adenylyl cyclase activator (NKH477; $200 \mathrm{ng} / 0.4 \mu \mathrm{l}$ ) or inhibitor (SQ22536; $200 \mathrm{ng} / 0.4 \mu \mathrm{l}$ ) into the vlPAG $20 \mathrm{~min}$ before each morphine or saline microinjection on Trials 1-6. On Trial 1, nociception was measured $30 \mathrm{~min}$ following morphine or saline microinjection. One day after the last pretreatment, a cumulative dosing procedure was used to assess the antinociceptive potency of microinjecting morphine or the $\mathrm{GABA}_{\mathrm{A}}$ antagonist bicuculline into the vlPAG. Cumulative quarter log doses of morphine were administered (to obtain final doses of $3.2,5.6,10$, and $18 \mu \mathrm{g} / 0.4 \mu \mathrm{l}$ ) at $20 \mathrm{~min}$ intervals. The hot plate test was conducted $15 \mathrm{~min}$ following each injection. Bicuculline cumulative dosing was done in a similar manner except third log doses $(4.6,10,22$, and $46 \mathrm{ng} / 0.4 \mu \mathrm{l}$ ) were administered at $7 \mathrm{~min}$ intervals and the hot plate test was conducted $5 \mathrm{~min}$ after each injection. These doses and injection times are known to produce dosedependent antinociception (Bobeck et al, 2009).

Histology and data analysis. Following testing, rats received a lethal dose of halothane. Brains were removed and stored in formalin (10\%) and sliced coronally $(100 \mu \mathrm{m})$ 2 days later to identify the location of the injection site. Only those injection sites in or adjacent to the vlPAG were included in data analysis (Bobeck et al, 2012) as shown in Supplementary Figure 1. Dose-response curves were plotted using GraphPad (Prism) and the half maximal antinociceptive effect $\left(D_{50}\right)$ was calculated for each group. The bottom limit was set as the average baseline score for all groups, and the top was set at the $50 \mathrm{~s}$ cutoff latency. No top constraint was set in the SQ22536 and bicuculline dose-response experiments because the maximal effect appeared to be $<50 \mathrm{~s}$ so that curve fits were tested for both $D_{50}$ and maximal response. Statistical significance $(\alpha<0.05)$ was tested with ANOVA. A Bonferroni post-hoc test was conducted when necessary.

\section{Electrophysiological Recordings}

Male Sprague-Dawley rats (Harlan laboratories; PN day $>30)$ received subcutaneous injections of saline $(1 \mathrm{ml} / \mathrm{kg})$ or morphine $(5 \mathrm{mg} / \mathrm{kg})$ twice daily for 3 days. Rats receiving continuous morphine were injected with a sustained release suspension of morphine base every other day for 5 days. Morphine base $(50 \mathrm{mg})$ was suspended in $0.1 \mathrm{ml}$ mannide mono-oleate (Arlacel A), $0.4 \mathrm{ml}$ mineral oil, and $0.5 \mathrm{ml} 0.9 \%$ $\mathrm{NaCl}$ (wt/vol) in water. Vehicle-treated animals were injected on the same schedule with a morphine-free suspension. The brain was removed for whole-cell patchclamp recordings 1-3 days after the last injection. Coronal 
slices $(220 \mu \mathrm{m})$ containing vlPAG were cut and maintained at $32{ }^{\circ} \mathrm{C}$ in physiological saline equilibrated with $95 \% \mathrm{O}_{2}$ and $5 \% \mathrm{CO}_{2}$ and then transferred to a small chamber $\left(32^{\circ} \mathrm{C}\right)$ for electrophysiological recording. The extracellular solution contained (in mM) $126 \mathrm{NaCl}, 2.5 \mathrm{KCl}, 1.2 \mathrm{MgCl}_{2}, 2.4$ $\mathrm{CaCl}_{2}, 1.2 \mathrm{NaH}_{2} \mathrm{PO}_{4}, 21.4 \mathrm{NaHCO}_{3}$, and 11.1 glucose $(\mathrm{pH}$ 7.35). Neurons from vlPAG were visualized with infrared Nomarski optics and whole-cell patch-clamp recordings were made with patch electrodes $(2-5 \mathrm{M} \Omega)$ with an internal solution containing (in $\mathrm{mM}$ ) $130 \mathrm{CsCl}, 10 \mathrm{HEPES}, 1.1 \mathrm{EGTA}$, $10 \mathrm{KCl}, 2 \mathrm{MgCl}_{2}, 0.1 \mathrm{CaCl}_{2}, 4 \mathrm{MgATP}, 1 \mathrm{NaGTP}$, and $0.3 \%$ biocytin $(\mathrm{pH} 7.4)$. Series resistance $(<12 \mathrm{M} \Omega)$ was compensated by $80 \%$ and continuously monitored throughout the experiment. Liquid junction potentials of $5 \mathrm{mV}$ were corrected. Data were acquired with Axograph X (Sydney, Australia) software. Spontaneous miniature inhibitory postsynaptic currents (mIPSCs) were obtained in the presence of TTX $(500 \mathrm{nM})$ and NBQX $(5 \mu \mathrm{M})$ filtered at $2 \mathrm{kHz}$ and sampled at $5 \mathrm{kHz}$. Events were detected using Axograph by selecting events that exceeded a preset threshold (set to $10-20 \mathrm{pA}$ ) and fit the criteria: $10-90 \%$ rise time $(0$ and $2 \mathrm{~ms})$ and half-width $(>3 \mathrm{~ms})$. Events were verified individually and ranked by amplitude and interevent interval to construct cumulative probability distributions. All distributions were tested for normality with Shapiro-Wilk normality test. Frequency was determined over 2 min epochs after equilibration of each drug. Mean mIPSC amplitudes were determined from Gaussian fits to amplitude histograms. All data are expressed as mean \pm STE. Statistical significance was determined in two group comparisons by paired $t$-tests or Mann-Whitney $U$-tests and in more than two group comparisons by one-way ANOVA or Kruskal-Wallis (nonparametric ANOVA) when appropriate $(p<0.05)$, followed by Bonferroni post-hoc tests or Dunn's multiple comparisons test (Graphpad Prism 4).

\section{RESULTS}

\section{Morphine Tolerance, but not Antinociception, Is Dependent on Adenylyl Cyclase Activation}

Microinjections of saline and morphine were targeted to the vlPAG (Supplementary Figure 1). Animals whose cannula placements were outside of the vlPAG were omitted from data analyses. Microinjection of morphine into the vlPAG produces antinociception as indicated by an increase in hot plate latency compared with saline-treated controls on Trial 1 (Figure $1 \mathrm{a} ; \mathrm{F}_{(5,49)}=18.47 ; p<0.05$ ). Morphineinduced antinociception was not altered with the adenylyl cyclase activator NKH477 or the adenylyl cyclase inhibitor SQ22536 microinjected $20 \mathrm{~min}$ before the morphine injection (Bonferroni, n.s.), nor did NKH477 or SQ22536 produce antinociception on their own (Bonferroni, n.s.). Repeated treatment with NKH477 or SQ22536 did not alter subsequent baseline nociception in the absence of drugs $\left(\mathrm{F}_{(5,45)}=0.51\right.$; n.s. $)$.

Repeated twice-daily microinjections of morphine for 3 days caused a rightward shift in the dose-response curve (Figure $1 \mathrm{~b} ; \mathrm{F}_{(3,160)}=19.38 ; p<0.05$; see Table 1 for $D_{50}$ values). Repeated adenylyl cyclase activation with NKH477 also caused a rightward shift in the morphine dose-response curve. The rightward shift in the morphine dose-response curve produced by prior co-administration of morphine and NKH477 was not different from the shift produced by repeated morphine injections alone indicating that repeated NKH477 induces a shift in the morphine dose-response curve by a similar mechanism as morphine pretreatment. Inhibition of adenylyl cyclase with SQ22536 20 min before each morphine pretreatment injection attenuated the rightward shift in the morphine dose-response curve. There was no difference in morphine potency in rats injected with both SQ22536 and morphine and control animals receiving SQ22536 alone (Figure 1c; $\mathrm{F}_{(1,76)}=0.31 ;$ n.s.). These results show that activating adenylyl cyclase mimics tolerance to morphine and blocking adenylyl cyclase prevents the development of morphine tolerance. Although there was a trend for reduced maximal effects of morphine in rats treated with SQ22536, the decrease was not significantly different between groups $\left(\mathrm{F}_{(3,168)}=2.127 ; p>0.05\right)$.

Microinjection of SQ22536 $20 \mathrm{~min}$ before the morphine dose-response curve on Trial 7 also blocked the expression of morphine tolerance. Morphine potency for morphinetolerant rats injected with SQ22536 was significantly greater than for morphine-tolerant animals that did not receive SQ22536 (Figure 1d; $\mathrm{F}_{(2,118)}=9.730 ; p<0.05$ ). These results indicate that blocking adenylyl cyclase activity is sufficient to reverse morphine tolerance. Inhibition of adenylyl cyclase activity may prevent morphine tolerance by reducing presynaptic GABA release. The following experiment tested this hypothesis by examining mIPSCs using whole-cell patch-clamp recordings in vlPAG slices.

\section{Activation of Adenylyl Cyclase Increases the Frequency of Presynaptic GABA Release and Decreases Opioid Inhibition of Release}

Activation of adenylyl cyclase with forskolin superfusion increased the frequency of mIPSCs in saline $(0.6-1.6 \mathrm{~Hz}$, $n=10$, Mann-Whitney $U$-test, $p<0.05)$ and morphine pretreated rats $(0.8-1.8 \mathrm{~Hz}, n=8$, Mann-Whitney $U$-test, $p<0.05$; Figure $2 \mathrm{a}$ and $\mathrm{b})$. There was no difference in basal mIPSC frequency between morphine $(n=8)$ and saline $(n=10)$ pretreated animals in the absence of forskolin administration (Figure 2b, Mann-Whitney U-test; n.s.). The water-soluble adenylyl cyclase activator NKH477 induced similar increases in mIPSC frequency as rats treated with forskolin (208 $\pm 79 \%$ increase, $n=3)$.

An $\mathrm{EC}_{50}$ concentration of $\left[\mathrm{met}^{5}\right]$-enkephalin (ME $300 \mathrm{nM}$; Ingram et al, 2008) was applied to determine whether forskolin-stimulated mIPSCs altered the inhibition by opioids (Figure 2c and d). ME inhibition of MIPSC frequency was significantly greater in control $(25 \pm 7 \%$ inhibition) compared with slices in the presence of forskolin $\left(13 \pm 4 \%\right.$; paired $t$-test, $\left.t_{(4)}=3.147 ; p<0.05\right)$. These results indicate that the ability of opioids to inhibit GABAergic mIPSCs is reduced when presynaptic GABA release is stimulated by adenylyl cyclase activation.

\section{Repeated Morphine Injections Alter Postsynaptic $\mathrm{GABA}_{\mathrm{A}}$ Receptor Responses}

Increased GABA release is known to occur in the vlPAG following continuous morphine administration (Ingram et al, 1998; Hack et al, 2003; Bagley et al, 2005). The objective of 
a

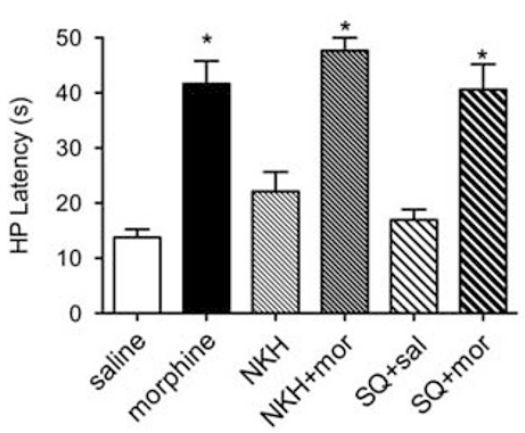

C

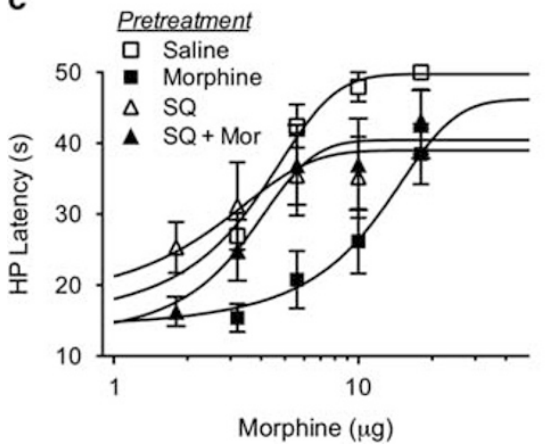

b

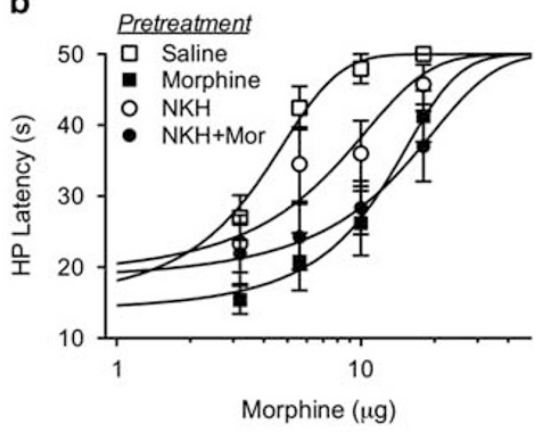

d

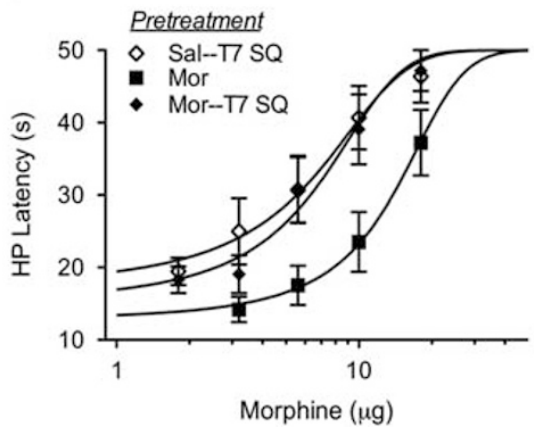

Figure I Adenylyl cyclase activation or inhibition alters the development of morphine tolerance, but not antinociception. (a) Rats were pretreated with

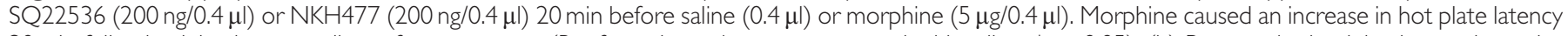
30 min following injection regardless of pretreatment (Bonferroni post-hoc test compared with saline; * $p<0.05$ ). (b) Repeated microinjections twice a day for 3 days of morphine $(5 \mu \mathrm{g} / 0.4 \mu \mathrm{l})$ or NKH477 (200 ng/0.4 $\mu \mathrm{l})$ causes a rightward shift in the morphine dose response compared with saline controls. (c) Pretreatment with SQ22536 $(200 \mathrm{ng} / 0.4 \mu \mathrm{l})$ in combination with morphine caused a leftward shift in the morphine dose-response curves compared with morphine alone $(5 \mu \mathrm{g} / 0.4 \mu \mathrm{l})$. (d) Microinjection of SQ22536 (200 ng/0.4 $\mu$ l) $20 \mathrm{~min}$ before the morphine microinjections on day 4 also reversed the shift in morphine pretreated rats.

Table I Effects of Adenylyl Cyclase Activation and Inhibition on Morphine- and Bicuculline-Induced Antinociception

\begin{tabular}{lcc}
\hline Pretreatment & Morphine $\boldsymbol{D}_{\mathbf{5 0}} \pm \mathbf{C l}(\mathbf{n})$ & Bicuculline $\boldsymbol{D}_{\mathbf{5 0}} \pm \mathbf{C I}(\boldsymbol{n})$ \\
\hline Saline & $3.4(2.8-4.0(7))$ & $9.5(5.7-13.3(9))$ \\
$\mathrm{NKH}$ & $5.9(3.7-8.0(8))^{\mathrm{a}}$ & $13.5(2.7-24.3(9))^{\mathrm{b}}$ \\
Morphine & $11.6(9.2-14.1(10))^{\mathrm{a}}$ & $15.6(7.8-23.4(7))^{\mathrm{b}}$ \\
$\mathrm{NKH}+$ Mor & $11.4(7.3-15.4(9))^{\mathrm{a}}$ & \\
SQ & $1.7(0.1-3.4(8))$ & \\
SQ + Mor & $3.3(1.9-4.6(8))$ & \\
Sal-SQT7 & $5.5(3.8-7.3(8))^{\mathrm{c}}$ & \\
Mor-SQT7 & $6.3(4.8-7.8(9))^{\mathrm{c}}$ & \\
\hline
\end{tabular}

Notes: Morphine $D_{50}$ values in $\mu$ g; Bicuculline $D_{50}$ values in $n g$.

Abbreviations: $\mathrm{Cl}, 95 \%$ confidence interval; $n$, number of rats.

${ }^{\text {a}}$ Statistically different from saline (morphine dose-response).

${ }^{b}$ Statistically different from saline (bicuculline dose-response).

'Statistically different from morphine alone (morphine dose-response).

this experiment was to determine whether repeated morphine injections produce a similar increase in basal mIPSC frequency. In contrast to our previous results with continuous morphine administration, basal GABAergic mIPSC frequency was not significantly different in saline $(0.9 \pm$ $0.3 \mathrm{~Hz}, n=11)$ compared with morphine pretreated rats $(0.9 \pm 0.3 \mathrm{~Hz}, n=13$; Figure $3 \mathrm{a}$ and $\mathrm{b})$ pretreated rats.
Spontaneous, action potential-dependent GABA release in the absence of tetrodotoxin was also similar in slices from saline $(1.5 \pm 0.4 \mathrm{~Hz}, \quad n=9)$ and morphine pretreated rats $(2.0 \pm 0.1 \mathrm{~Hz}, n=4$; Mann-Whitney $U$-test; n.s.). Further analyses of the mIPSCs showed differences in the amplitude of mIPSC events (Figure $3 \mathrm{c}-\mathrm{f}$ ). A cumulative frequency plot combining all cells in the saline and morphine groups clearly shows a shift to smaller amplitude events in slice recordings from the morphine pretreated rats. Gaussian fits to the histograms show a significant decrease in the mean amplitude in slices from morphine pretreated rats $(32 \pm 2 \mathrm{pA}, n=13)$ compared with saline pretreated rats $(45 \pm 6 \mathrm{pA}, n=10$; $\left.t_{(21)}=2.258 ; p<0.05\right)$. The rise time and decay kinetics of the mIPSCs were not significantly altered in morphine pretreated rats (data not shown). Taken together, these results indicate that there is a loss of large amplitude mIPSCs in the vlPAG following morphine pretreatment and that postsynaptic $\mathrm{GABA}_{\mathrm{A}}$ receptors are modulated in morphine-tolerant rats.

We superfused the adenylyl cyclase inhibitor SQ22536 $(10-20 \mu \mathrm{M})$ to assess whether the changes in neurons from morphine pretreated rats were due to upregulated adenylyl cyclase activity. SQ22536 significantly inhibited basal mIPSC frequency by $29 \pm 8 \%$ without affecting neurons from naïve rats $\left(1 \pm 3 \%\right.$ inhibition; $t_{(13)}=4.087 ; p<0.05$; Figure $3 g$ ). In addition, SQ22536 reversed the decrease in mean amplitude of basal mIPSCs in slices from morphine pretreated rats (32 pA shown in Figure $3 \mathrm{f}$ ) to $51 \pm 5 \mathrm{pA}$ $(n=5)$. This effect was only observed in slices from 


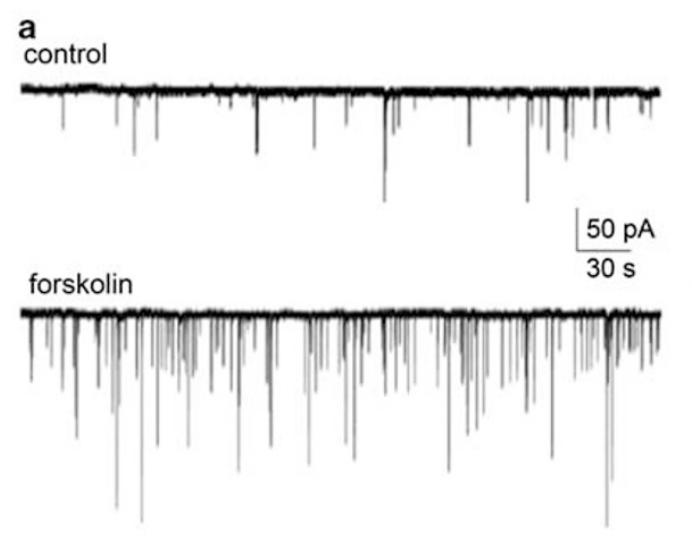

C

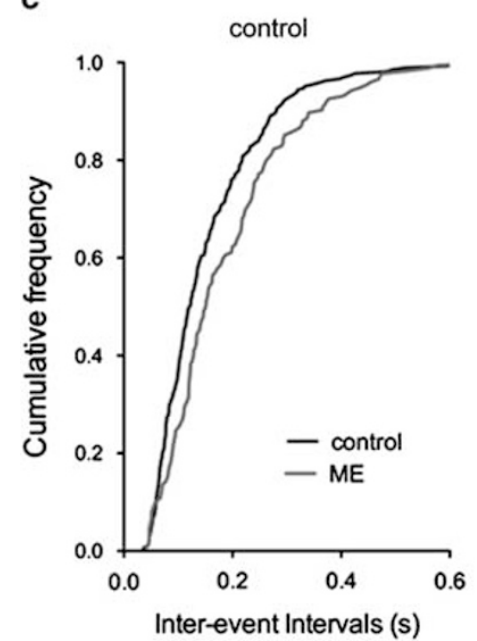

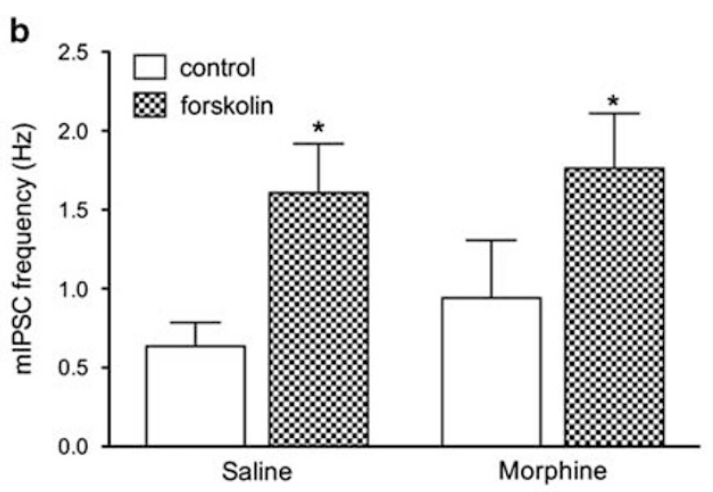

d

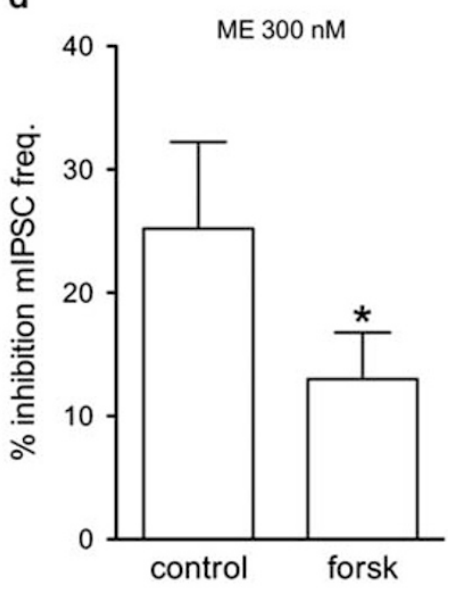

Figure 2 Activation of adenylyl cyclase increases presynaptic GABA release and decreases opioid inhibition of GABA release. (a) Representative traces of isolated GABAergic mIPSCs in control and forskolin (IO $\mu \mathrm{M}$ ) showing increased frequency of mIPSC events. (b) Bar graph showing forskolin-induced increases in mIPSC frequency in slices from both saline and morphine pretreated rats. (c) Cumulative frequency plots from a single experiment showing a decreased frequency with ME (300 nM) that is abolished after superfusion of the slice in forskolin ( $10 \mu \mathrm{M})$. (d) Summary data for inhibition by ME (300 nM) in control and forskolin ( $P<0.05$; paired $t$-test, $n=5$ ).

morphine pretreated rats as SQ22536 increased the mean amplitude by $35 \pm 4 \%$ compared with negligible effects in naïve rats $\left(5 \pm 9 \% ; t_{(13)}=2.309 ; p<0.05\right.$; Figure $\left.3 \mathrm{~h}\right)$. These results suggest that inhibition of adenylyl cyclase activity decreases the probability of release of GABA from presynaptic terminals and reduces postsynaptic $\mathrm{GABA}_{\mathrm{A}}$ responses selectively in morphine pretreated rats.

\section{Inhibition of Adenylyl Cyclase Alters Responses after Chronic Morphine Administration}

In order to determine whether adenylyl cyclase inhibition affects GABAergic neurotransmission after chronic morphine administration, rats were pretreated with a slow release suspension for 5 days. This paradigm induces profound tolerance and strong dependence characterized by withdrawal behaviors (Ingram et al, 1998; Bagley et al, 2011). Slices were either withdrawn immediately after cutting in the absence of morphine for $>2 \mathrm{~h}$ or maintained in morphine $(5 \mu \mathrm{M})$. Vehicle pretreated rats had a basal mIPSC frequency $(0.4 \pm 0.1 \mathrm{~Hz}, n=5)$ similar to saline injections $(0.6 \pm 0.2 \mathrm{~Hz}, n=10)$. In contrast, basal mIPSC frequency $(1.2 \pm 0.3 \mathrm{~Hz}, n=4)$ in slices from morphine pretreated rats that were spontaneously withdrawn was faster and was reduced $35 \pm 4 \%$ by superfusion of SQ22536. Basal mIPSC amplitudes were $28 \pm 4 \mathrm{pA}$ and were unaffected by SQ22536 (26 $26 \mathrm{pA})$. As shown previously, in slices from morphine pretreated rats maintained in morphine, naloxone superfusion $(1.5 \pm 0.3 \mathrm{~Hz}$ in the presence of naloxone compared with $0.7 \pm 2 ; n=5$ ) increased the frequency of mIPSCs (Figure 4). SQ22536 reversed this increase in mIPSC frequency $(0.9 \pm 0.1 \mathrm{~Hz}$, Kruskal-Wallis, $p<0.05$ ).

\section{Morphine and NKH477 Decrease Bicuculline-Induced Antinociception}

To behaviorally assess changes in GABA synaptic transmission in the vlPAG, we measured antinociception induced by microinjections of the $\mathrm{GABA}_{\mathrm{A}}$ antagonist, bicuculline. Bicuculline produces antinociception by inhibiting $\mathrm{GABA}_{\mathrm{A}}$ receptors on postsynaptic vlPAG output neurons. There was no significant difference in baseline hot plate latencies following pretreatment with saline, NKH477, morphine, or SQ22536 $\left(\mathrm{F}_{(3,33)}=0.24\right.$; n.s. $)$. Repeated vlPAG activation of adenylyl cyclase with microinjections of NKH477 altered the 
a

Saline

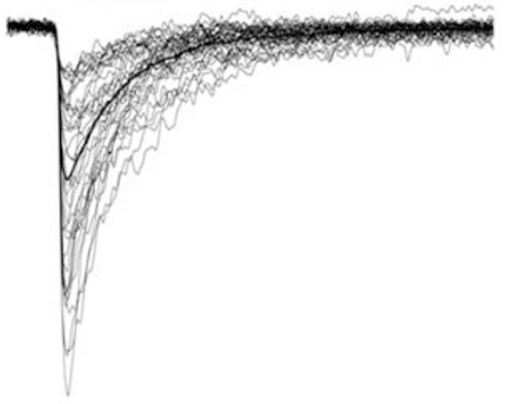

c

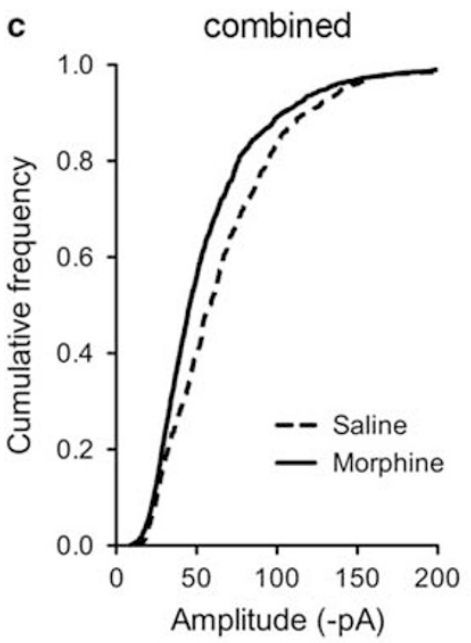

f

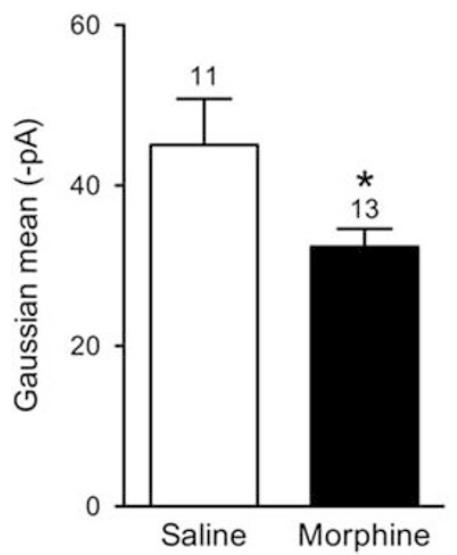

Morphine

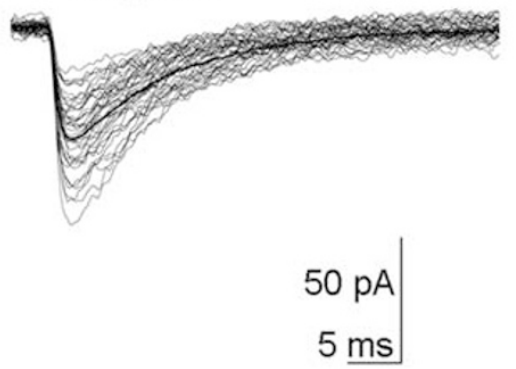

d Saline pretreatment

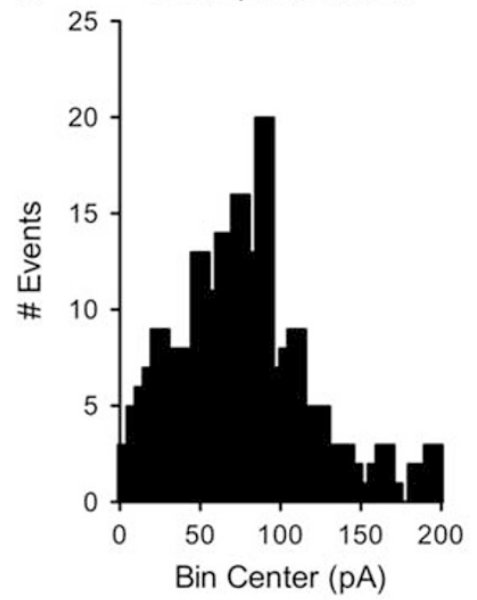

g

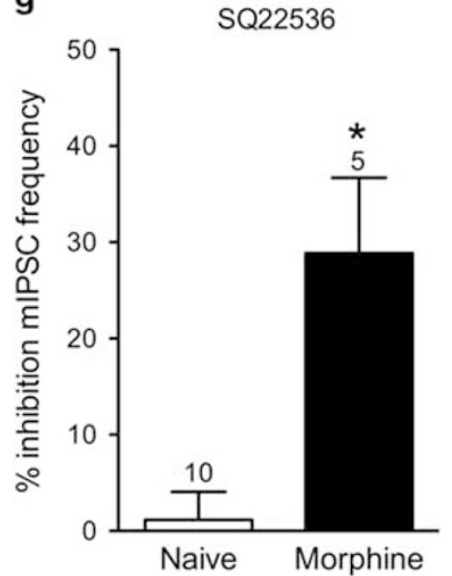

b

combined

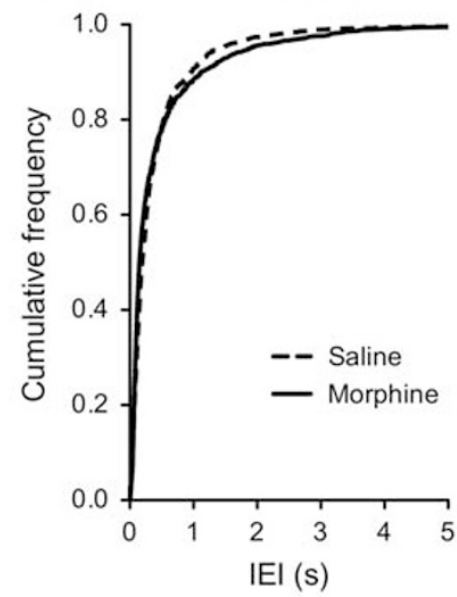

e Morphine pretreatment

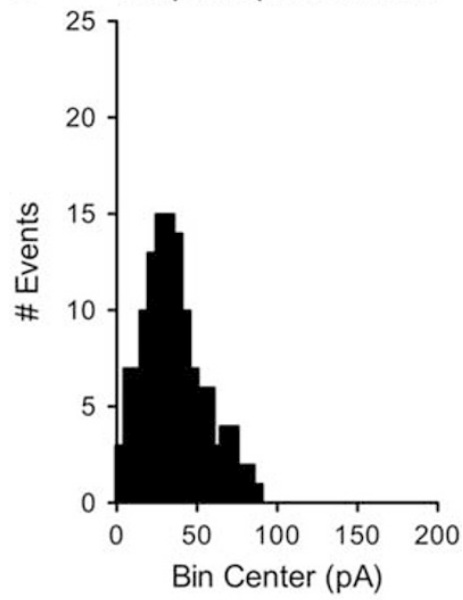

h

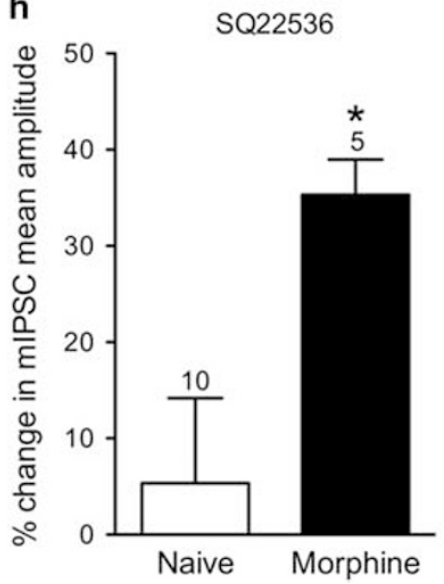

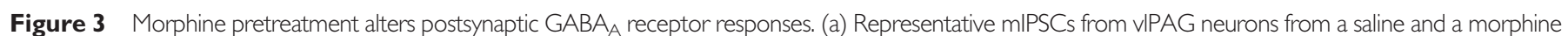
pretreated rat. Bold trace is average of all traces. (b) A cumulative frequency plot combining all neurons from saline $(n=10)$ and morphine $(n=13)$ rats showing that basal mIPSC frequency was not different in slices from saline or morphine pretreated rats. (c) A cumulative frequency plot of mIPSC amplitudes showed a shift toward smaller amplitudes in the morphine group. ( $\mathrm{d}$ and e) Amplitude histograms from individual experiments show that mIPSC amplitudes are shifted to the left after morphine pretreatment. (f) Gaussian fits to histograms estimated mean amplitude of mIPSCs. Mean amplitudes of mIPSCs from morphine pretreated rats were significantly smaller than from saline-pretreated slices $(* p<0.05)$. (g) SQ22536 inhibited mIPSC frequency in slices from morphine pretreated rats but had no effect in naïve animals. (h) SQ22536 increased the mean amplitude of spontaneous mIPSCs in morphine-tolerant but not in naiive slices.

bicuculline dose response curve when both maximal effect and $D_{50}$ values were compared (two-way ANOVA; $\mathrm{F}_{(4,118)}=5.881 ; p<0.05$; Figure $\left.4 \mathrm{~d}\right)$. Post-hoc analyses show that dose-response curves were significantly shifted to the right (loss of potency) in animals pretreated with morphine or NKH477 compared with saline (Table 1). The maximal 
a
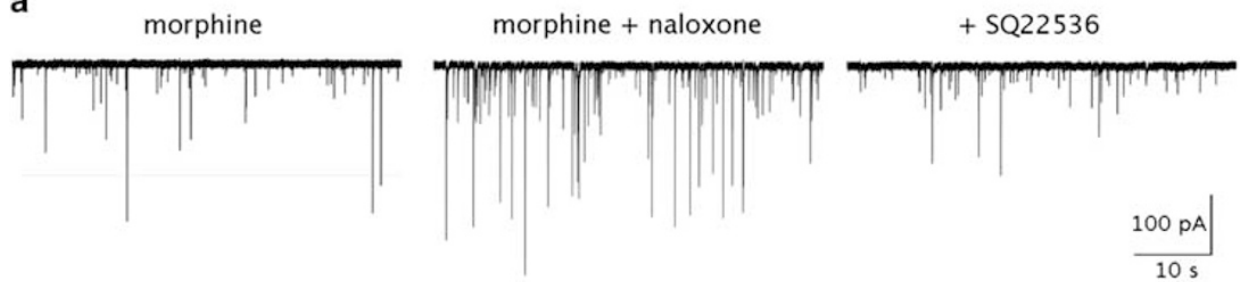

b

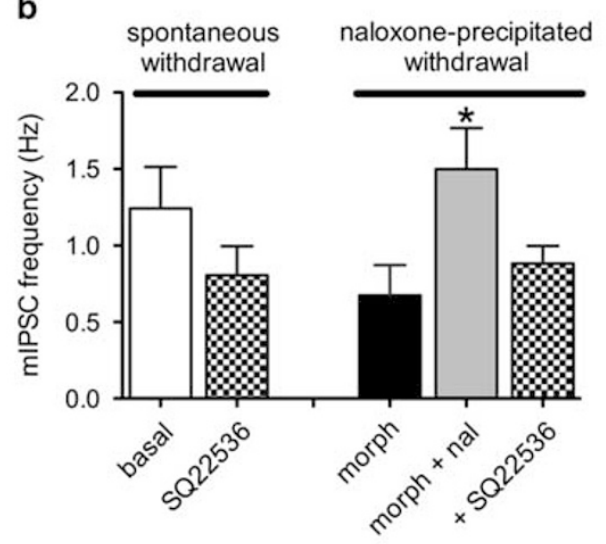

d

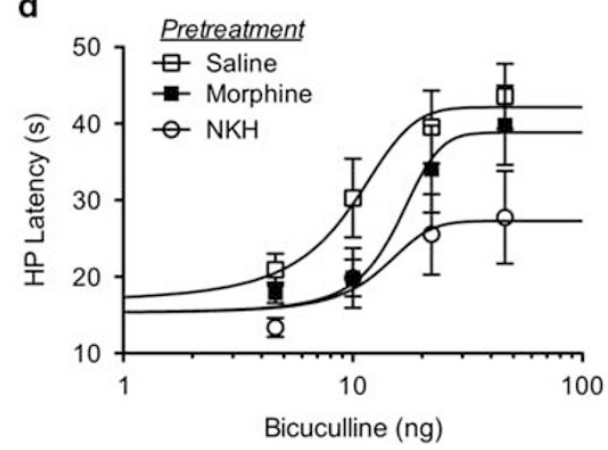

c

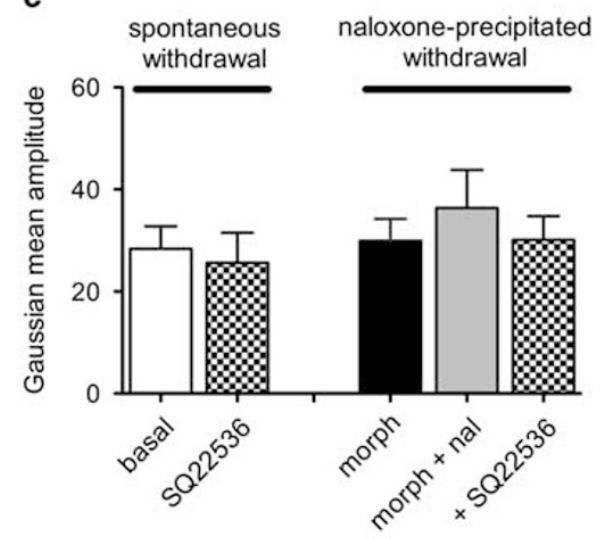

Figure 4 Continuous morphine administration increases mIPSC frequency. (a) Slices were maintained in morphine (5 $\mu M$ ) after cutting. Representative

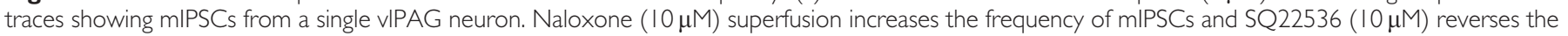

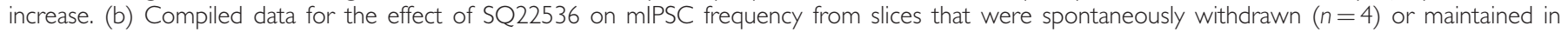

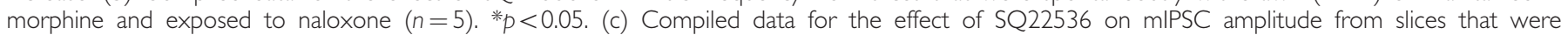

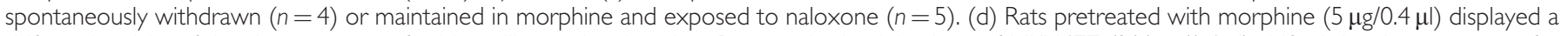

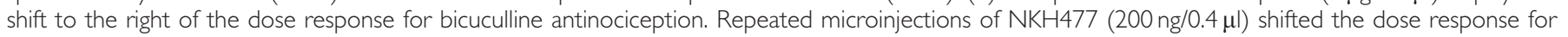
bicuculline and decreased the maximal antinociception induced by bicuculline.

antinociception was decreased in animals pretreated with NKH477 (27 s; CI: 21-33 s) compared with saline (42 s; CI: 37-48 s) and morphine (39s, CI: 8-23 s; one-way ANOVA; $\left.\mathrm{F}_{(2,118)}=5.330 ; p<0.05\right)$ pretreated rats. These results indicate that activation of adenylyl cyclase decreases activation of $\mathrm{GABA}_{\mathrm{A}}$ receptors in the vlPAG.

\section{DISCUSSION}

The present data demonstrate that activation of adenylyl cyclase in the vlPAG mimics morphine tolerance and blocking adenylyl cyclase reverses morphine tolerance. In addition, activation of adenylyl cyclase modulates both presynaptic GABA release and postsynaptic $\mathrm{GABA}_{\mathrm{A}}$ receptor responses. Altered postsynaptic $\mathrm{GABA}_{\mathrm{A}}$ receptor currents are a novel observation that may be a critical component underlying decreased opioid-induced antinociception in morphine tolerance. Consistent with these data, repeated morphine and NKH477 administration shift the doseresponse curve for bicuculline-mediated antinociception to the right. Thus, antinociceptive tolerance induced by repeated morphine administration into the vlPAG is associated with both presynaptic and postsynaptic adaptations in GABA neurotransmission.

\section{Signaling Pathways for MOP-Induced Antinociception are Different in Naïve and Morphine-Tolerant Animals}

Repeated and chronic administration of opioids induce compensatory upregulation of adenylyl cyclase and its downstream messenger cyclic adenosine monophosphate (Sharma et al, 1975; Gintzler and Chakrabarti, 2008; Shy et al, 2008). Inhibition of the adenylyl cyclase-PKA pathway 
during morphine pretreatment blocks the development of morphine tolerance ( $\mathrm{Ma}$ and Pan, 2006; Gabra et al, 2008) and dependence (Punch et al, 1997; Li et al, 2006). Based on these studies, we hypothesized that activation of adenylyl cyclase alone could induce tolerance. Interestingly, a single injection of the adenylyl cyclase activator NKH477 was not sufficient to alter hot plate latencies in morphine-naïve animals. This result is consistent with studies showing that administration of PKA and PKC inhibitors block morphine tolerance but do not affect acute opioid-induced antinociception (Punch et al, 1997; Gabra et al, 2008). We also observed no effect of the adenylyl cyclase inhibitor SQ22536 on mIPSC frequency or amplitude from opioid-naïve slices. These results show that acute activation of adenylyl cyclase does not decrease morphine-induced antinociception, even though we find that activation of adenylyl cyclase with forskolin increases presynaptic GABA release and reduces the effective inhibition of release by ME (see Figure 2). A single microinjection of NKH477 may not upregulate adenylyl cyclase activity enough to affect antinociception but repeated activation is sufficient to significantly shift the morphine dose response curve to the right.

Antinociception elicited by the PAG is thought to be a result of MOP inhibition of GABA release in the vlPAG by presynaptic MOPs (Fields et al, 1983; Heinricher and Ingram, 2008). However, MOPs are also localized to the cell bodies and dendrites of a subpopulation of vlPAG neurons (Commons et al, 2000). These postsynaptic MOPs are thought to decrease GABA interneuron activity to facilitate activation of PAG-RVM output neurons (Osborne et al, 1996) but there may also be a role for these receptors in modulating postsynaptic $\mathrm{GABA}_{\mathrm{A}}$ receptors, similar to results in the nucleus tractus solitarius (Herman et al, 2012).

MOPs in presynaptic terminals signal via phospholipase A2-mediated activation of voltage-gated potassium channels (Vaughan et al, 1997), signaling that is not dependent on adenylyl cyclase activation (Ingram et al, 2008). However, MOP signaling in GABAergic presynaptic terminals shifts from phospholipase A2-dependent signaling to adenylylPKA-dependent signaling following continuous morphine administration (Ingram et al, 1998). This switch to the adenylyl cyclase-PKA signaling pathway has been shown to contribute to naloxone-precipitated withdrawal behaviors (Bagley et al, 2011). Consistent with these previous studies, microinjections of SQ22536 either with morphine during the development of tolerance or on Trial 7 blocked the rightward shift in the morphine dose-response curve in morphine pretreated animals. In addition to enhancing morphine-induced antinociception and reversing morphine tolerance, the adenylyl cyclase inhibitor SQ22536 inhibited mIPSC frequency and reversed the decrease in mean mIPSC amplitude observed in morphine pretreated rats without affecting either measure in saline pretreated rats. In morphine-dependent rats, SQ22536 also reversed the naloxone-dependent increase in mIPSC frequency. Therefore, the role of adenylyl cyclase in modulating antinociception becomes more prominent with repeated or continuous morphine administration implying that the compensatory changes that occur in GABA neurotransmission in the vlPAG may be effective targets for drugs that block tolerance to the analgesic effects of opioids.

\section{Cellular Changes Associated with Morphine Tolerance and Dependence Are Dissociable in the vlPAG}

Many of the previous studies looking at cellular changes associated with morphine tolerance, including studies from our laboratory, used continuous morphine administration for 3-5 days that produce strong naloxone-precipitated withdrawal behaviors. Even repeated administration paradigms using high doses and/or more days of exposure produce significant withdrawal behaviors (Madhavan et al, 2010). Route of administration also affect severity and degree of morphine tolerance (Dighe et al, 2009). Several lines of evidence indicate that our morphine administration paradigm, twice daily morphine microinjections for 3 days, does not induce the same cellular adaptations and behavioral outcomes as continuous morphine administration. First, our tolerance paradigm does not induce appreciable withdrawal behaviors to injections of naloxone compared with behaviors elicited by naloxone following continuous administration (Ingram et al, 2008). The lack of an effect of naloxone indicates that morphine and endogenous opioids are not present in the rats at the time of preparing slices. Second, we observe no naloxone-precipitated cellular changes in our slice recordings. This finding indicates that our treatment paradigm does not induce constitutive MOP activity observed with continuous morphine administration and withdrawal in other brain areas (Shoblock and Maidment, 2006; Meye et al, 2012). Third, in the current study, we did not observe increased spontaneous GABA release from morphine pretreated rats using repeated morphine injections as we, and others, observe using continuous morphine administration (Ingram et al, 1998; Hack et al, 2003; Bagley et al, 2005; Ma and Pan, 2006). Thus, although it is clear in the behavioral experiments that we are inducing upregulation of the adenylyl cyclase pathway with repeated microinjections of morphine, we do not observe an increased probability of basal GABA release from presynaptic terminals unless we use the continuous morphine administration paradigm. We also did not observe a difference in spontaneous GABA release in the absence of tetrodotoxin in rats pretreated with repeated intermittent morphine injections. This finding does not rule out the possibility that evoked GABA release is enhanced in the intact system and contributes to the observed decrease in morphine and bicuculline antinociception. In fact, enhanced evoked release may explain the decrease in opioid potency for inhibiting evoked GABAergic IPSCs observed in the vlPAG in morphine-tolerant rats (Fyfe et al, 2010).

The lack of a change in basal GABA release with our repeated morphine administration paradigm helped to reveal compensatory changes in mIPSC amplitude in tolerant animals. The amplitude histogram of GABAergic mIPSCs was shifted to the left indicating that large amplitude events were depleted, but that the number of smaller events were increased in morphine-tolerant animals. We have interpreted the shift in the amplitude histogram as a loss of larger mIPSCs rather than a decrease in amplitude of all mIPSCs because we did not observe a decrease in mIPSC frequency in the morphine-tolerant slices; events did not decrease in amplitude to the point that smaller events were lost in the noise. In fact, the cumulative 
frequency of mIPSC amplitudes less that $40 \mathrm{pA}$ was not significantly different between saline and morphine pretreated slices. The larger mIPSCs may represent multiquantal release, release of GABA from non-synaptic sites, or a subpopulation of $\mathrm{GABA}_{\mathrm{A}}$ receptors with different subunit compositions (Richerson and $\mathrm{Wu}, 2003$; Mody and Pearce, 2004; Glykys and Mody, 2007). Future experiments are focused on how morphine pretreatment alters postsynaptic $\mathrm{GABA}_{\mathrm{A}}$ receptors to distinguish between these possibilities. MOP regulation of $\mathrm{GABA}_{\mathrm{A}}$ receptors has not been observed in the vlPAG previously but regulation of extrasynaptic $\mathrm{GABA}_{\mathrm{A}}$ receptors has been described in mouse nucleus tractus solitarius neurons (Herman et al, 2012). Herman and colleagues show evidence that the MOP-selective agonist, DAMGO, inhibits tonic $\mathrm{GABA}_{\mathrm{A}}$-mediated currents. Most MOP agonists induce superactivation of adenylyl cyclase activity with repeated and continuous administration (Avidor-Reiss et al, 1996; Zhao et al, 2006). MOPselective agonists DAMGO and fentanyl also induce antinociceptive tolerance with repeated microinjections into the ventrolateral PAG (Meyer et al, 2007; Bobeck et al, 2012). Further, cross-tolerance to antinociception between morphine and sufentanil has been observed (Nowoczyn et al, 2013), suggesting common signaling pathways between different opioid agonists. Thus, it is possible that opioid regulation of $\mathrm{GABA}_{\mathrm{A}}$ receptors may be an important regulatory system in many opioid-sensitive brain areas.

\section{Morphine and AC Activation Decrease Bicuculline- Induced Antinociception}

Many adaptations in MOP signaling are associated with morphine tolerance (Williams et al, 2013) so it is difficult to parse out changes in MOP signaling from changes in the downstream GABAergic signaling that are key to the diminished opioid antinociception. We used bicucullinemediated antinociception as a measure of MOP-independent antinociception to isolate changes in GABAergic neurotransmission from adaptations in MOP signaling in morphine-tolerant animals. Bicuculline induces antinociception because it is a competitive inhibitor of postsynaptic $\mathrm{GABA}_{\mathrm{A}}$ receptors. Both repeated morphine and NKH477 administration shift the dose-response curve for bicuculline antinociception to the right. These data indicate that either presynaptic GABA release is potentiated in morphine pretreated rats or that there is a change in the affinity of GABA (or bicuculline) for $\mathrm{GABA}_{\mathrm{A}}$ receptors in morphinetolerant animals. The adenylyl cyclase-PKA pathway has been shown to be a signaling pathway involved in postsynaptic $\mathrm{GABA}_{\mathrm{A}}$ receptor modulation (Porter et al, 1990; Moss et al, 1992) and trafficking (Chen et al, 2006) so it is possible that trafficking of $\mathrm{GABA}_{\mathrm{A}}$ receptors is modulated by opioids and that changes in activation of postsynaptic $\mathrm{GABA}_{\mathrm{A}}$ receptors are critical adaptations underlying decreased opioid antinociception associated with morphine tolerance. Alternatively, the postsynaptic decrease in $\mathrm{GABA}_{\mathrm{A}}$ receptor responses may be a compensatory change that is secondary to increased presynaptic GABA release in vivo. Further studies are necessary to identify which $\mathrm{GABA}_{\mathrm{A}}$ receptors are modulated by repeated morphine administration to further understand their role in modulating antinociception.

\section{CONCLUSION}

The finding that both presynaptic GABA release and postsynaptic $\mathrm{GABA}_{\mathrm{A}}$ receptors in the vlPAG are modulated in morphine tolerance is significant because it will help to unravel the myriad of compensatory changes that have been associated with morphine tolerance. Moreover, these data suggest that adenylyl cyclase inhibitors and allosteric $\mathrm{GABA}_{\mathrm{A}}$ agonists (Llorente et al, 2013) may be targets for rational drug design for improved opioid antinociception with less tolerance. We show that increased adenylyl cyclase activity can induce tolerance to morphine but that it does not significantly modulate antinociception with a single injection. Repeated and continuous administration of morphine induces adaptations that alter both presynaptic GABA release (Ingram et al, 1998; Hack et al, 2003; Bagley et al, 2005; Bagley et al, 2011) and postsynaptic $\mathrm{GABA}_{\mathrm{A}}$ receptor function (this paper). Previous studies have demonstrated that other G-protein-coupled receptors, such as dopamine D2 and D3 receptors, modulate $\mathrm{GABA}_{\mathrm{A}}$ receptor trafficking via modulation of PKA (Chen et al, 2006) and PKC (Herring et al, 2005). Both of these signaling pathways are modulated by MOPs and have been implicated in morphine tolerance (Williams et al, 2013). Thus, multiple signaling pathways may target different aspects of MOP modulation of GABA neurotransmission to affect antinociception (Garzon et al, 2008). Further studies of MOP regulation of $\mathrm{GABA}_{\mathrm{A}}$ receptor signaling and trafficking in vlPAG neurons are necessary to determine how to determine the best targets for new analgesic drugs.

\section{FUNDING AND DISCLOSURE}

The authors declare no conflict of interest.

\section{ACKNOWLEDGEMENTS}

We thank Katherine L Suchland and Rachel A Reid for excellent technical assistance for behavioral studies. Research was funded by National Institutes of Health: National Institute of Drug and Alcohol Abuse (DA015498 (ENB, MMM) and DA027625 (SLI, MMM)).

\section{REFERENCES}

Avidor-Reiss T, Nevo I, Levy R, Pfeuffer T, Vogel Z (1996). Chronic opioid treatment induces adenylyl cyclase V superactivation. Involvement of Gbetagamma. J Biol Chem 271: 21309-21315.

Bagley EE, Gerke MB, Vaughan CW, Hack SP, Christie MJ (2005). GABA transporter currents activated by protein kinase A excite midbrain neurons during opioid withdrawal. Neuron 45: 433-445.

Bagley EE, Hacker J, Chefer VI, Mallet C, McNally GP, Chieng BC et al (2011). Drug-induced GABA transporter currents enhance GABA release to induce opioid withdrawal behaviors. Nat Neurosci 14: 1548-1554.

Bobeck EN, Haseman RA, Hong D, Ingram SL, Morgan MM (2012). Differential development of antinociceptive tolerance to morphine 
and fentanyl is not linked to efficacy in the ventrolateral periaqueductal gray of the rat. J Pain 13: 799-807.

Bobeck EN, McNeal AL, Morgan MM (2009). Drug dependent sexdifferences in periaqueducatal gray mediated antinociception in the rat. Pain 147: 210-216.

Chen G, Kittler JT, Moss SJ, Yan Z (2006). Dopamine D3 receptors regulate GABAA receptor function through a phospho-dependent endocytosis mechanism in nucleus accumbens. J Neurosci 26: 2513-2521.

Commons KG, Aicher SA, Kow LM, Pfaff DW (2000). Presynaptic and postsynaptic relations of mu-opioid receptors to gammaaminobutyric acid-immunoreactive and medullary-projecting periaqueductal gray neurons. J Comp Neurol 419: 532-542.

Dighe SV, Madia PA, Sirohi S, Yoburn BC (2009). Continuous morphine produces more tolerance than intermittent or acute treatment. Pharmacol Biochem Behav 92: 537-542.

Fields HL, Basbaum AI, Heinricher MM (2005). Central nervous system mechanisms of pain modulation. In: McMahon S, Koltzenburg M (Eds.). Textbook of Pain, 5th ed. Elsevier Health Sciences: Burlington, Massachusetts, USA, 125-142.

Fields HL, Vanegas H, Hentall ID, Zorman G (1983). Evidence that disinhibition of brain stem neurones contributes to morphine analgesia. Nature 306: 684-686.

Fyfe LW, Cleary DR, Macey TA, Morgan MM, Ingram SL (2010). Tolerance to the antinociceptive effect of morphine in the absence of short-term presynaptic desensitization in rat periaqueductal gray neurons. J Pharmacol Exp Ther 335: 674-680.

Gabra BH, Bailey CP, Kelly E, Smith FL, Henderson G, Dewey WL (2008). Pre-treatment with a PKC or PKA inhibitor prevents the development of morphine tolerance but not physical dependence in mice. Brain Res 1217: 70-77.

Garzon J, Rodriguez-Munoz M, Sanchez-Blazquez P (2008). Do pharmacological approaches that prevent opioid tolerance target different elements in the same regulatory machinery? Curr Drug Abuse Rev 1: 222-238.

Gintzler AR, Chakrabarti S (2008). The ambiguities of opioid tolerance mechanisms: barriers to pain therapeutics or new pain therapeutic possibilities. J Pharmacol Exp Ther 325: 709-713.

Glykys J, Mody I (2007). The main source of ambient GABA responsible for tonic inhibition in the mouse hippocampus. J Physiol 582: 1163-1178.

Hack SP, Vaughan CW, Christie MJ (2003). Modulation of GABA release during morphine withdrawal in midbrain neurons in vitro. Neuropharmacology 45: 575-584.

Heinricher MM, Ingram SL (2008). The brainstem and nociceptive modulation. In: The Senses: A Comprehensive Reference. Academic Press: Elsevier: London, pp 593-626.

Herman MA, Gillis RA, Vicini S, Dretchen KL, Sahibzada N (2012). Tonic GABAA receptor conductance in medial subnucleus of the tractus solitarius neurons is inhibited by activation of mu-opioid receptors. J Neurophysiol 107: 1022-1031.

Herring D, Huang R, Singh M, Dillon GH, Leidenheimer NJ (2005). PKC modulation of GABAA receptor endocytosis and function is inhibited by mutation of a dileucine motif within the receptor beta 2 subunit. Neuropharmacology 48: 181-194.

Ingram SL, Macey TA, Fossum EN, Morgan MM (2008). Tolerance to repeated morphine administration is associated with increased potency of opioid agonists. Neuropsychopharmacology 33: 2494-2504.

Ingram SL, Vaughan CW, Bagley EE, Connor M, Christie MJ (1998). Enhanced opioid efficacy in opioid dependence is caused by an altered signal transduction pathway. J Neurosci 18: 10269-10276.

Jacquet YF, Lajtha A (1974). Paradoxical effects after microinjection of morphine in the periaqueductal gray matter in the rat. Science 185: 1055-1057.

Jolas T, Nestler EJ, Aghajanian GK (2000). Chronic morphine increases GABA tone on serotonergic neurons of the dorsal raphe nucleus: association with an up-regulation of the cyclic AMP pathway. Neuroscience 95: 433-443.

Lane DA, Patel PA, Morgan MM (2005). Evidence for an intrinsic mechanism of antinociceptive tolerance within the ventrolateral periaqueductal gray of rats. Neuroscience 135: 227-234.

Li S, Lee ML, Bruchas MR, Chan GC, Storm DR, Chavkin C (2006). Calmodulin-stimulated adenylyl cyclase gene deletion affects morphine responses. Mol Pharmacol 70: 1742-1749.

Llorente J, Withey S, Rivero G, Cunningham M, Cooke A, Saxena K et al (2013). Ethanol reversal of cellular tolerance to morphine in rat locus coeruleus neurons. Mol Pharmacol 84: 252-260.

Ma J, Pan ZZ (2006). Contribution of brainstem GABA(A) synaptic transmission to morphine analgesic tolerance. Pain 122: 163-173.

Madhavan A, He L, Stuber GD, Bonci A, Whistler JL (2010). Microopioid receptor endocytosis prevents adaptations in ventral tegmental area GABA transmission induced during naloxoneprecipitated morphine withdrawal. J Neurosci 30: 3276-3286.

Meye FJ, van Zessen R, Smidt MP, Adan RA, Ramakers GM (2012). Morphine withdrawal enhances constitutive mu-opioid receptor activity in the ventral tegmental area. J Neurosci 32: 16120-16128.

Meyer PJ, Fossum EN, Ingram SL, Morgan MM (2007). Analgesic tolerance to microinjection of the micro-opioid agonist DAMGO into the ventrolateral periaqueductal gray. Neuropharmacology 52: $1580-1585$.

Mody I, Pearce RA (2004). Diversity of inhibitory neurotransmission through GABA(A) receptors. Trends Neurosci 27: 569-575.

Morgan MM, Clayton CC, Boyer-Quick JS (2005). Differential susceptibility of the PAG and RVM to tolerance to the antinociceptive effect of morphine in the rat. Pain 113: 91-98.

Morgan MM, Clayton CC, Lane DA (2003). Behavioral evidence linking opioid-sensitive GABAergic neurons in the ventrolateral periaqueductal gray to morphine tolerance. Neuroscience 118: 227-232.

Morgan MM, Fossum EN, Levine CS, Ingram SL (2006). Antinociceptive tolerance revealed by cumulative intracranial microinjections of morphine into the periaqueductal gray in the rat. Pharmacol Biochem Behav 85: 214-219.

Morgan MM, Whittier KL, Hegarty DM, Aicher SA (2008). Periaqueductal gray neurons project to spinally projecting GABAergic neurons in the rostral ventromedial medulla. Pain 140: 376-386.

Moss SJ, Smart TG, Blackstone CD, Huganir RL (1992). Functional modulation of GABAA receptors by cAMP-dependent protein phosphorylation. Science 257: 661-665.

Nowoczyn M, Marie N, Coulbault L, Hervault M, Davis A, Hanouz JL et al (2013). Remifentanil produces cross-desensitization and tolerance with morphine on the mu-opioid receptor. Neuropharmacology 73: 368-379.

Osborne PB, Vaughan CW, Wilson HI, Christie MJ (1996). Opioid inhibition of rat periaqueductal grey neurones with identified projections to rostral ventromedial medulla in vitro. $J$ Physiol 490(Pt 2): 383-389.

Porter NM, Twyman RE, Uhler MD, Macdonald RL (1990). Cyclic AMP-dependent protein kinase decreases GABAA receptor current in mouse spinal neurons. Neuron 5: 789-796.

Punch LJ, Self DW, Nestler EJ, Taylor JR (1997). Opposite modulation of opiate withdrawal behaviors on microinfusion of a protein kinase A inhibitor versus activator into the locus coeruleus or periaqueductal gray. J Neurosci 17: 8520-8527.

Richerson GB, Wu Y (2003). Dynamic equilibrium of neurotransmitter transporters: not just for reuptake anymore. J Neurophysiol 90: 1363-1374.

Sharma SK, Klee WA, Nirenberg M (1975). Dual regulation of adenylate cyclase accounts for narcotic dependence and tolerance. Proc Natl Acad Sci USA 72: 3092-3096.

Shoblock JR, Maidment NT (2006). Constitutively active micro opioid receptors mediate the enhanced conditioned aversive 


\section{Changes in GABA signaling with morphine tolerance}

EN Bobeck et al

effect of naloxone in morphine-dependent mice. Neuropsychopharmacology 31: 171-177.

Shy M, Chakrabarti S, Gintzler AR (2008). Plasticity of adenylyl cyclase-related signaling sequelae after long-term morphine treatment. Mol Pharmacol 73: 868-879.

Tortorici V, Robbins CS, Morgan MM (1999). Tolerance to the antinociceptive effect of morphine microinjections into the ventral but not lateral-dorsal periaqueductal gray of the rat. Behav Neurosci 113: 833-839.

Vaughan CW, Ingram SL, Connor MA, Christie MJ (1997). How opioids inhibit GABA-mediated neurotransmission. Nature 390: 611-614.
Wang L, Gintzler AR (1995). Morphine tolerance and physical dependence: reversal of opioid inhibition to enhancement of cyclic AMP formation. J Neurochem 64: 1102-1106.

Williams JT, Ingram SL, Henderson G, Chavkin C, von Zastrow M, Schulz S et al (2013). Regulation of mu-opioid receptors: desensitization, phosphorylation, internalization, and tolerance. Pharmacol Rev 65: 223-254.

Zhao H, Loh HH, Law PY (2006). Adenylyl cyclase superactivation induced by long-term treatment with opioid agonist is dependent on receptor localized within lipid rafts and is independent of receptor internalization. Mol Pharmacol 69: 1421-1432.

Supplementary Information accompanies the paper on the Neuropsychopharmacology website (http://www.nature.com/npp) 